\title{
Fretting behaviour of galvanised steel
}

\author{
M.C. Gaspar ${ }^{\mathrm{a}}$, A. Ramalho ${ }^{\mathrm{b}, *}$ \\ ${ }^{a}$ Escola Superior de Tecnologia, Instituto Politécnico de Castelo Branco, Av. do Empresário, 6000 Castelo Branco, Portugal \\ ${ }^{\mathrm{b}}$ Departamento de Engenharia Mecânica, Faculdade de Ciências e Tecnologia da Universidade de Coimbra, \\ Pinhal de Marrocos, 3030 Coimbra, Portugal
}

Received 2 February 2001; received in revised form 4 October 2001; accepted 17 October 2001

\begin{abstract}
The present work describes research conducted on the fretting behaviour of S 355 MC galvanised steel sheet. In order to study the influence of the normal load and the displacement effect, some of the specimens were galvanised by hot dipping and the rest were only polished before being tested. Fretting tests were carried out on a specially developed fretting rig prototype under 'crossed-cylinders' contact geometry. Tests were done during $0.72 \times 10^{6}$ cycles in laboratory air conditions. The tangential force and the displacement were measured in order to establish the fretting cycles for each fretting condition. The fretted surfaces were analysed by means of optical and scanning electron microscopes to identify the main wear mechanisms. Three different fretting regimes were identified: the stick regime; the slip regime; and the mixed stick-slip regime, which depended mainly on the influence of the normal load and the stroke. (C) 2002 Elsevier Science B.V. All rights reserved.
\end{abstract}

Keywords: Fretting; Coatings; Surface treatments; Galvanisation

\section{Introduction}

Fretting is a phenomenon found in many technical systems when contacts are affected by small amplitude vibrations. Syntheses by Waterhouse [1], Bill [2] and Vincent et al. [3] have shed light on our understanding of its characteristics. Experimental work has been carried out on both bulk materials and on coated ones, and some authors have used Mindlin and Deresiewicz's [4], and Hamilton and Goodman's [5] approach to describe the contact. Its main limitation is that its application is restricted to materials with linear elastic behaviour. There is a lack of models for coated materials that can be easily and widely used to describe the tribo-contact behaviour more accurately. Experimental work is thus the most suitable solution to describe the fretting behaviour of coated materials and to achieve their corresponding fretting maps.

Galvanising is a surface treatment widely used to protect steel sheets used in the automotive industry [6], and hot dipping has become the solution for protecting cars' structure. Considering that a vehicle's structure has many bolted and riveted joints to connect various parts to the main frame, which is submitted to dynamic loads, fretting is a potential

\footnotetext{
* Corresponding author. Tel.: +351-239-790-700; fax: +351-239-790-701.

E-mail address: amilear.ramalho@dem.uc.pt (A. Ramalho).
}

type of damage, occurring isolated or acting to accelerate fatigue. As far as the authors are aware, little work has been done on this subject [7].

In the present work, the influence of the fretting stroke and the normal load on the fretting behaviour were both considered in order to analyse the wear mechanisms of the selected materials and to build up the corresponding fretting maps.

\section{Experimental procedures}

\subsection{Materials and fretting specimens}

The test specimens were machined from S 355 MC steel sheet (EN 10149) to the dimensions of $12 \mathrm{~mm} \times 7 \mathrm{~mm} \times 3 \mathrm{~mm}$ with one $12 \times 3$ face machined to a cylindrical surface of $12.5 \mathrm{~mm}$ radius. The specimens were divided into two groups, one group was hot dip galvanised at $450{ }^{\circ} \mathrm{C}$, and, as a result, a film with a thickness of approximately $130 \mu \mathrm{m}$ was deposited. Both types of specimen were polished; the coated specimens to a surface roughness of $R_{\mathrm{a}}=0.25 \mu \mathrm{m}$, and the uncoated ones to $R_{\mathrm{a}}=0.34 \mu \mathrm{m}$. The $\mathrm{S} 355 \mathrm{MC}$ cold hardened steel sheet had an ultimate strength of $459 \mathrm{MPa}$, a yield stress of $352 \mathrm{MPa}$ and a hardness of $131 \mathrm{HV}_{30}$. The micro hardness value measured at the surface of the coating was $80 \mathrm{HV}_{0.05}$. 


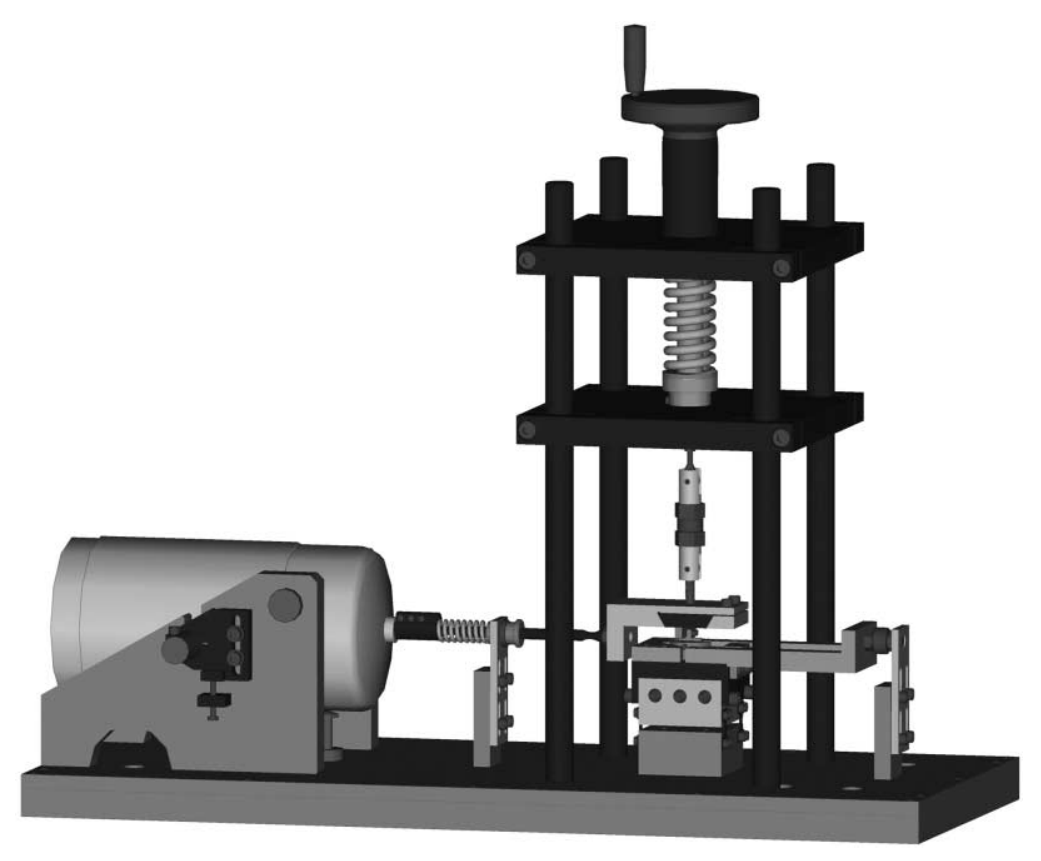

Fig. 1. Prototype fretting rig.

\subsection{Fretting rig}

The fretting tests were carried out on a specially developed fretting wear rig, schematically shown in Fig. 1. The influence of the various fretting parameters and the state of the art of this type of test machine were borne in mind during the development of this rig. This test machine is an imposed displacement type, which uses an electromagnetic actuator to apply a displacement between test specimens. Even though the specimens tested in the work described here had a specific geometry, specimens with a variety of forms and dimensions can be tested in this test rig. The maximum value of the fretting stroke depends on the test frequency and on the friction force amplitude. The maximum typical values used on the rig are $200 \mu \mathrm{m}$ (at $200 \mathrm{~Hz}$ ). The lower specimen can be heated by resistive heaters to allow high temperature tests. A closed chamber and a suitable control system permits tests to be carried out while changing and controlling the relative humidity.

The fretting rig consists of three main units: the control unit, the test unit and the data acquisition and processing unit. An Instron controller comprises of a control unit, with a feedback signal from a LVDT transducer that provides a PID control on the fretting stroke. The test unit consists of an electromagnetic actuator rigidly connected to the upper specimen by means of an arm and a specimen holder. The normal load is imposed on the upper test specimens by means of a spring compressed by a spindle, supported by a rigid frame. The system that applies the normal load includes a force sensor to measure the imposed normal load. The lower specimen is supported on a thermally and electrically insulated table to allow the measurement of the electric contact resistance. This table is separated from the main frame of the machine by vertical blades that restrict two degrees of freedom so that a piezoelectric load cell can read the effective tangential force in the contact of the fretting pair. An isolation chamber allows the imposition of different test atmospheres, including the control of relative humidity. The data acquisition unit allows the on-line acquisition of the fretting parameters that are being measured by the sensors, and also their subsequent processing.

\subsection{Fretting tests}

The fretting tests were carried out under the conditions given in Table 1, using crossed cylinder geometry with a radius of $12.5 \mathrm{~mm}$ on both surfaces. Prior to testing, the specimens were cleaned using a solvent solution. In order to identify the most promising conditions, a preliminary set of tests was carried out to check different values of fretting frequency, displacement amplitude and normal load. A more exhaustive series of tests was subsequently undertaken to study the effect of the normal load and the fretting stroke on the two tested pairs. The wear scars were assessed

Table 1

Fretting test conditions

\begin{tabular}{ll}
\hline Normal load $(\mathrm{N})$ & $2.5-30$ \\
Fretting stroke $(\mu \mathrm{m})$ & $4-100$ \\
Frequency $(\mathrm{Hz})$ & 100 \\
Test duration $($ cycles $)$ & $0.72 \times 10^{6}$ \\
Temperature $\left({ }^{\circ} \mathrm{C}\right)$ & $22 \pm 3$ \\
Atmosphere & Laboratory air \\
Relative humidity $(\%)$ & $50 \pm 5$ \\
\hline
\end{tabular}


Table 2

Contact stresses

\begin{tabular}{|c|c|c|c|c|c|c|}
\hline \multirow[t]{2}{*}{ Normal load (N) } & \multicolumn{2}{|c|}{$\emptyset$ Hertz contact $(\mu \mathrm{m})$} & \multicolumn{2}{|l|}{$\sigma_{\max }(\mathrm{MPa})$} & \multicolumn{2}{|l|}{$\sigma_{\max } / \sigma_{\mathrm{c}}$} \\
\hline & Non-coated & Galvanised & Non-coated & Galvanised & Non-coated & Galvanised \\
\hline 2.5 & 119.7 & 130.1 & 333 & 198.5 & 0.946 & 5.364 \\
\hline 5 & 150.8 & 162.2 & 420 & 250.1 & 1.193 & 6.758 \\
\hline 10 & 189.9 & 202.0 & 529 & 315.0 & 1.503 & 8.515 \\
\hline 20 & 239.3 & 251.9 & 667 & 396.9 & 1.895 & 10.728 \\
\hline 30 & 274 & 285.4 & 763 & 454.4 & 2.168 & 12.228 \\
\hline
\end{tabular}

using two- and three-dimensional profilometry to evaluate their transversal area, and optical and scanning electron microscopy (SEM) were used to identify the morphology of the wear surfaces.

The normal load used in this study ranged from 2.5 to $30 \mathrm{~N}$ and the Hertz maximum pressure at the start of the tests varied from 330 to $760 \mathrm{MPa}$, Table 2 . The radius of the Hertzian contact of the galvanised specimens have been corrected, using Halling's approach [8], to take into account the effect of the zinc film. In the calculations of the contact stress, the following values of the yield stress and of elastic modulus have been considered: for the substrate $352 \mathrm{MPa}$ and $210 \mathrm{GPa}$, and for the zinc film $37 \mathrm{MPa}$ and $96.5 \mathrm{GPa}$ [9]. Therefore, in the most of the tests the contact pressure is significantly larger than the yield stress.

In order to establish the test conditions suitable for undertaking this fretting study, it was verified beforehand that the size of the elastic contact, calculated according to the Hertz theory, was substantially larger than the imposed fretting stroke, in the different test conditions, Table 2.

\section{Results and discussion}

\subsection{Normal load}

In order to study the effect of the normal load on fretting behaviour, a set of tests was carried out on both uncoated and galvanised steels. The fretting strokes were constant for all the tests, having a value of $20 \mu \mathrm{m}$, and the parameter under study, the normal load, ranged from 2.5 to $30 \mathrm{~N}$. The wear scars revealed three different morphologies. For the higher values of the normal load, neither the galvanised nor uncoated steel, showed any trace of damage. For the intermediate values of the normal load, the scars exhibit maximum wear at the contact borders and minimum wear at the centre, thus the wear surfaces have an annular shape, as represented in Fig. 2. For the smallest values of the normal load, however, the wear was more intense and extended to the whole circular contact area (Fig. 3). The assessment of surface topography that is represented in Fig. 4 confirms the features observed with the scanning microscope. Fig. 5 summarises the role of the normal load on the damage features observed on the wear scars for the uncoated and for the galvanised steel.

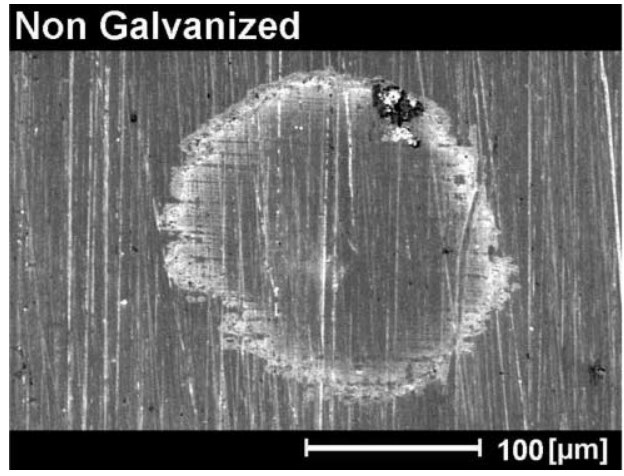

Fig. 2. SEM of a $5 \mathrm{~N}$ and $20 \mu \mathrm{m}$ fretting test scar.

During the fretting tests, the values of the tangential force and the relative displacement of the tribo-pairs were recorded in order to build up the corresponding fretting cycle. In Figs. 6 and 7, the fretting cycles of the $2.5 \mathrm{~N}$ and $30 \mathrm{~N}$ normal load condition tests are presented. For both galvanised and non-galvanised materials, the tests carried out with a load of $2.5 \mathrm{~N}$ reveal an evolution of the cycle shape from a more elliptic shape on the first cycles to a trapezoidal form on the final cycle of the test. Otherwise, for the tests carried out with higher values of the normal load, the shape of the fretting cycles remain elliptic during the entire test.

Vingsbo and Sodërberg [10] mapped the sliding domains that correspond to different contact interacting conditions. Three contact regimes have been identified, which are as follows:

- stick regime, corresponding to a quasi elastic contact, thus a non-dissipating regime;

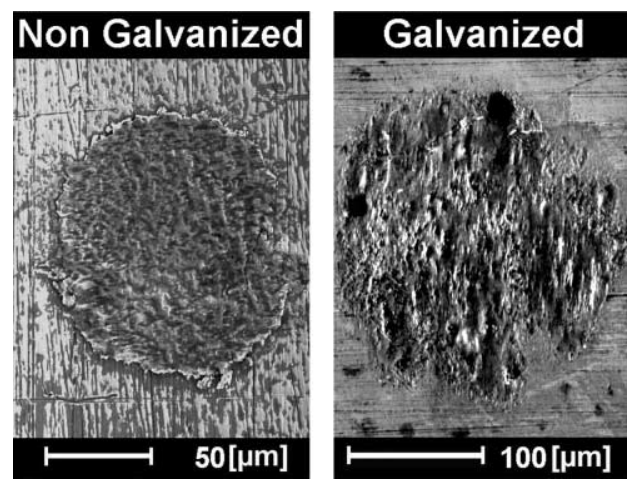

Fig. 3. SEM of $2.5 \mathrm{~N}$ and $20 \mu \mathrm{m}$ fretting tests scars. 


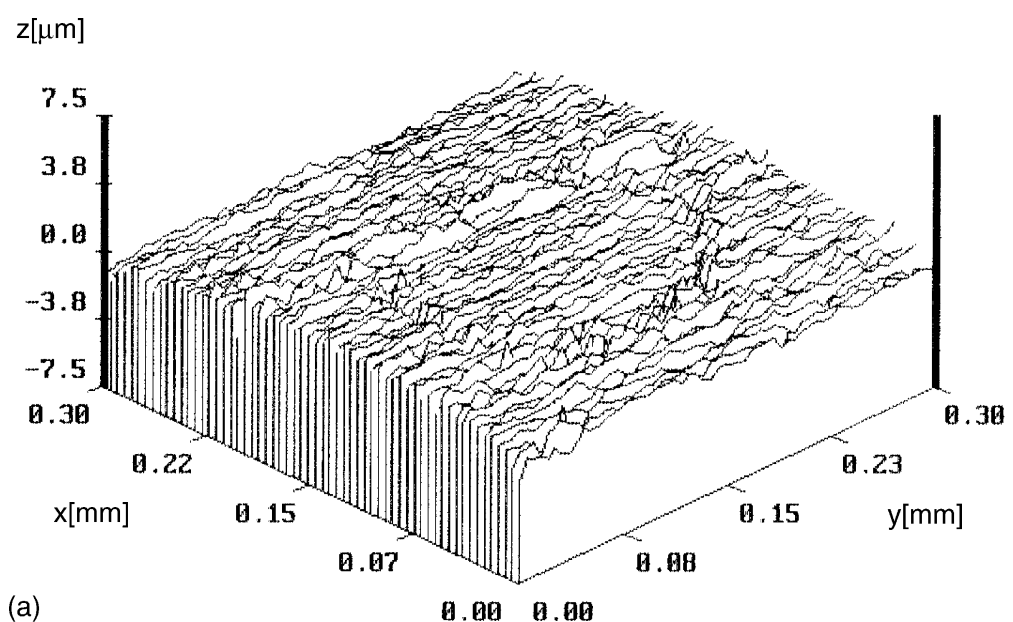

(a)

9.00 0.00

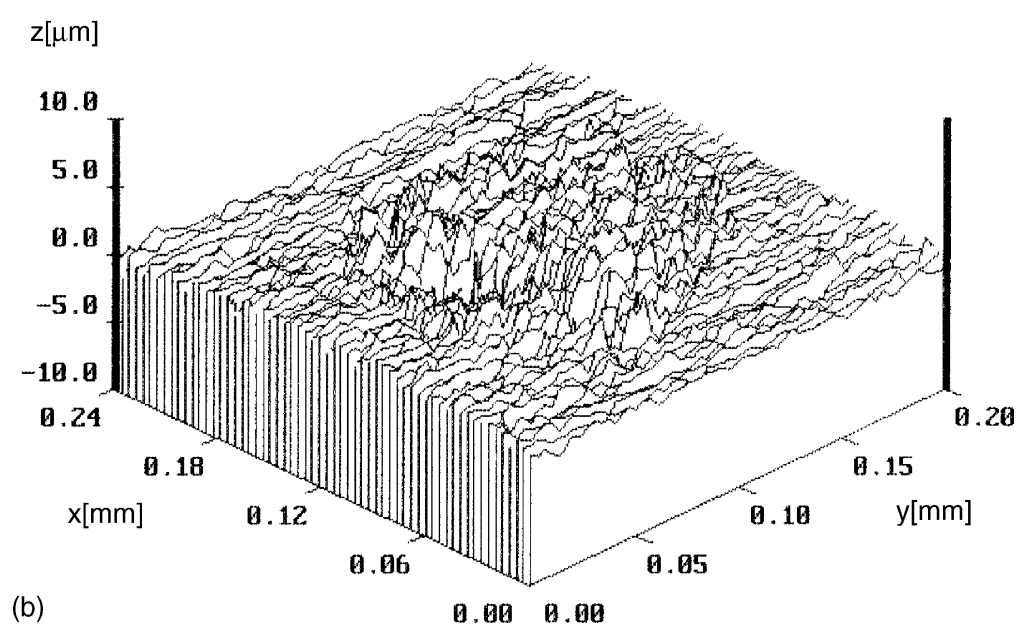

Fig. 4. Three-dimensional topography of a non-galvanised specimen for a $10 \mathrm{~N}$ and $20 \mu \mathrm{m}$ fretting test (a) and three-dimensional topography of a non-galvanised specimen for a $2.5 \mathrm{~N}$ and $20 \mu \mathrm{m}$ fretting test (b).

- partial slip regime, characterised by slip at the border of the contact area, with a small quantity of dissipated energy;

- gross slip, where the slip is spread over the entire contact area with significant amounts of dissipated energy.

Vincent et al. [3], combined the maps of the fretting regimes with the material response and concluded that there are two main damage mechanisms, the wear induced by

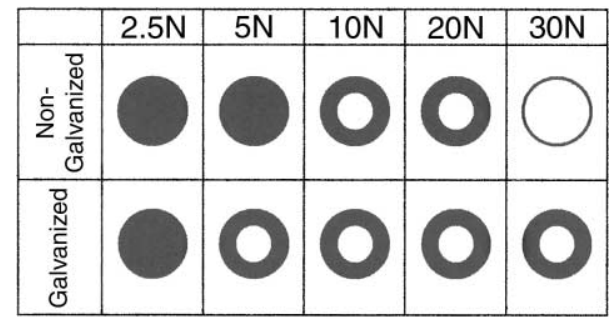

Fig. 5. Schematic representation of the damage features for the various normal load conditions tests (O) damage on the whole contact extent; (O) damage on the outer contact annulus; $(\bigcirc)$ no damage. debris formation, occurring mostly in the gross slip regime, and cracking formation in the stick regime. In the mixed regime, there is competition between these two regimes, and the surface is worn in an annular area corresponding to the outermost part of the contact area.

The results of our work, therefore, agree with the main published results. According to the elastic model of contacting spheres (Mindlin [4]), the stroke value, $\delta_{t}$, that corresponds to the transition from partial to gross slip, can be calculated by the expression (1). This expression shows that the transition value is linearly proportional to the friction coefficient and to the normal load, thus justifying the results obtained

$\delta_{\mathrm{t}}=\frac{3 \mu P}{8 a}\left(\frac{2-v}{G}\right)$

where $\delta_{\mathrm{t}}$ is the stroke value corresponding to the transition from partial slip to gross slip, $\mu$ the friction coefficient, $a$ the Hertzian contact radius, $P$ the normal load, $v$ and $G$ are the Poisson coefficient and the shear elastic modulus, respectively. 

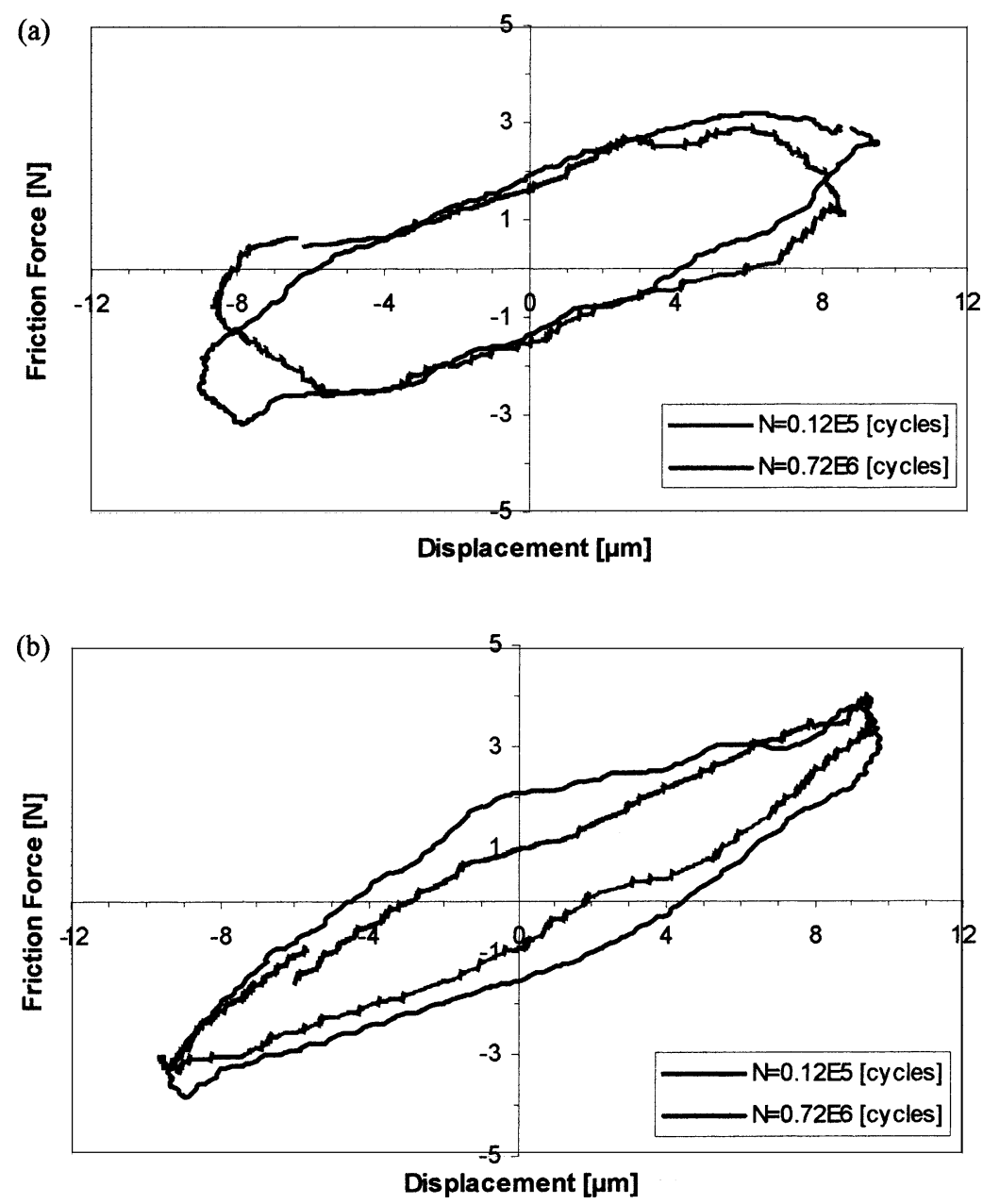

Fig. 6. Fretting logs corresponding to the $2.5 \mathrm{~N}$ load condition tests for the non-galvanised (a) and galvanised (b) specimens.

In spite of the agreement between the trend of the experimental results and the predicted by Mindlin's model, there is a significant difference in the stroke value corresponding to the threshold of gross slip. The main reason for that difference is the effect of the compliance of each experimental system that leads to an increase of the measured displacement relatively to the actual ones.

The amount of wear was evaluated by taking the middle profile of the scar, as represented in Fig. 4, and measuring its transverse area. The results, represented in Fig. 8, show that both tested materials exhibit the same behaviour. For the lowest value of the normal load, $2.5 \mathrm{~N}$, the amount of wear is at a maximum, afterwards it drops significantly as the normal load increases, remaining constant when the applied load is greater than $10 \mathrm{~N}$.

The area of the fretting cycles, Figs. 6 and 7, corresponds to the work exercised by the friction force; as such, it is a measure of the input energy in the system and has been correlated with the quantity of worn material by Campbell et al. [11]. This concept is now often used to study different materials [12-15]. When related to the amount of wear
(Fig. 9), the total energy dissipated by the friction force shows that only for the lower values of the normal load applied, corresponding to the gross slip regime, does the total energy have a significant value.

As expected, for the higher values of the normal load, where a mixed fretting regime has been identified, the dissipated energy remains virtually ignored, corresponding to a conservative contact. For the low values of dissipated energy arising from the contact conditions used in the study of the normal load, both the coated and uncoated specimens obey the same law.

\subsection{Fretting stroke}

Besides the normal load, the amplitude of the relative displacement is certainly the operation parameter with the stronger effect on the fretting behaviour. To study the effect of the displacement amplitude on the fretting behaviour of galvanised and non-coated steel, fretting tests were carried out, keeping the normal load of $20 \mathrm{~N}$ constant and applying a displacement amplitude that ranged from 4 to $100 \mu \mathrm{m}$. 

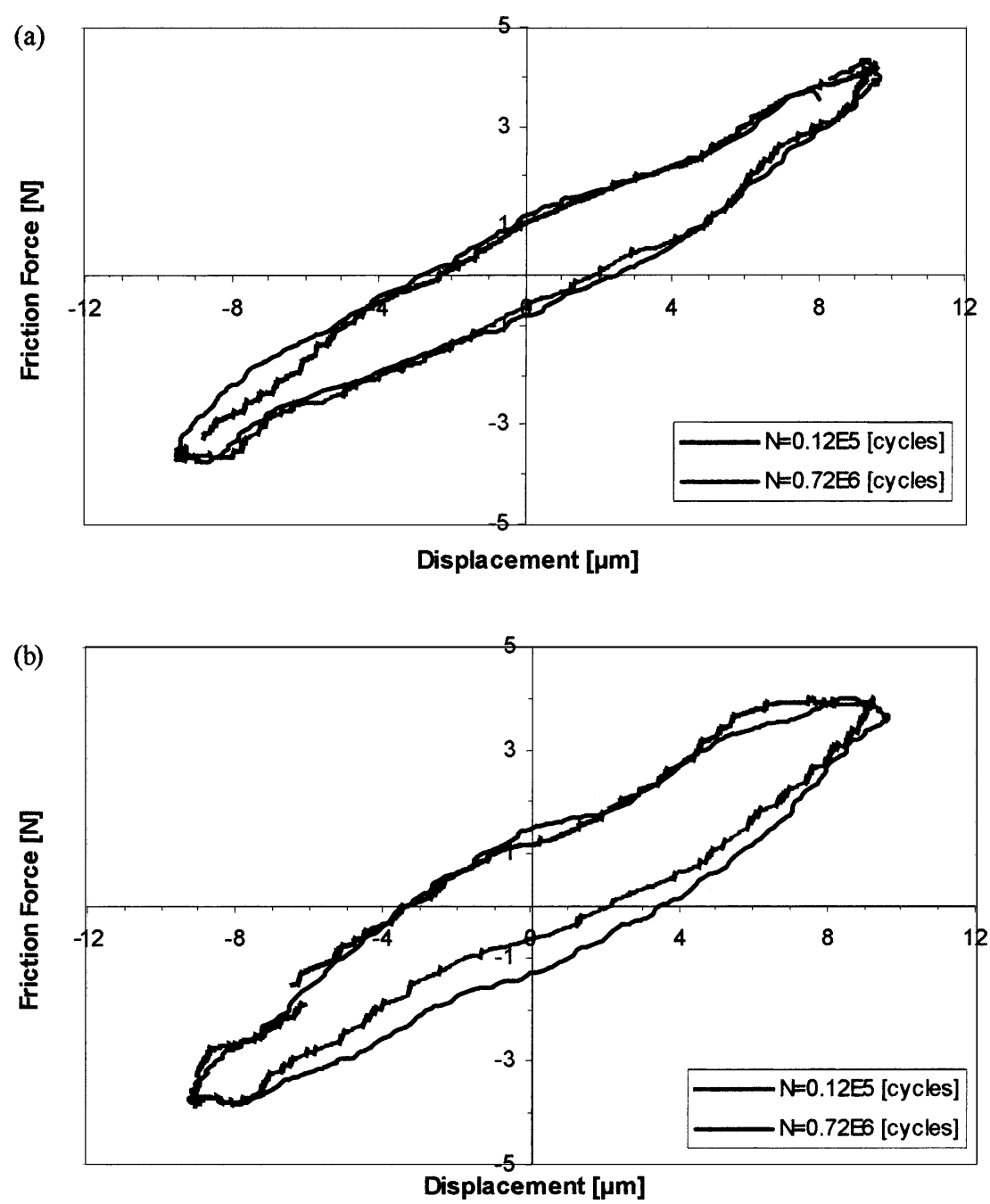

Fig. 7. Fretting logs corresponding to the $30 \mathrm{~N}$ load condition tests for the non-galvanised (a) and galvanised (b) specimens.

The morphology of the wear scars reveals that the three types of feature identified previously, under the normal load effect, also occur when the stroke is varied. Thus, for the highest value of stroke, the wear extended to the whole contact circle, whereas for the lower displacements no damage was observed. A damage mechanism characterised by annular wear at the edges of the contact circle has been identified for the intermediate values of the relative

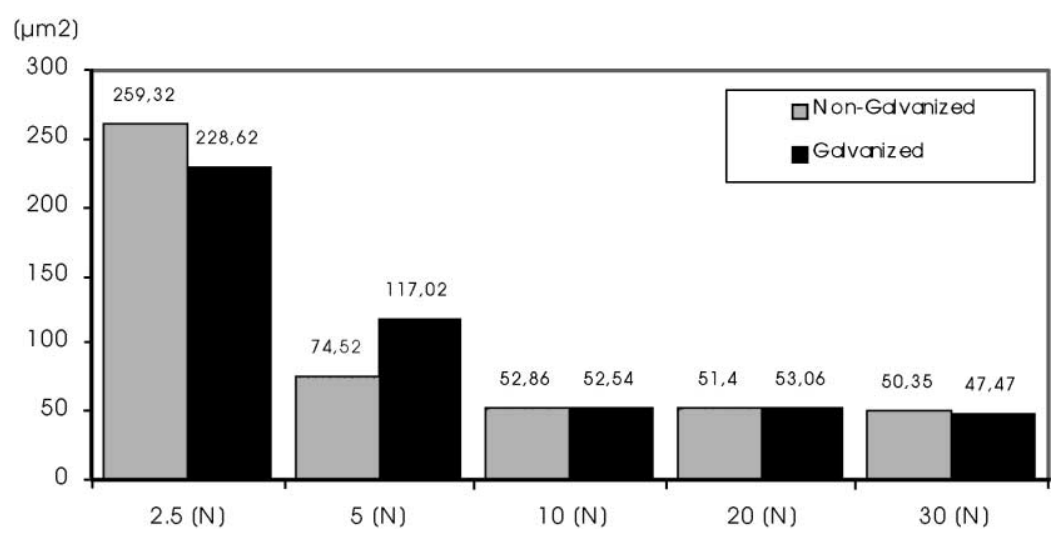

Fig. 8. Transversal area of the centre of the fretting scars for the various normal load condition tests. 


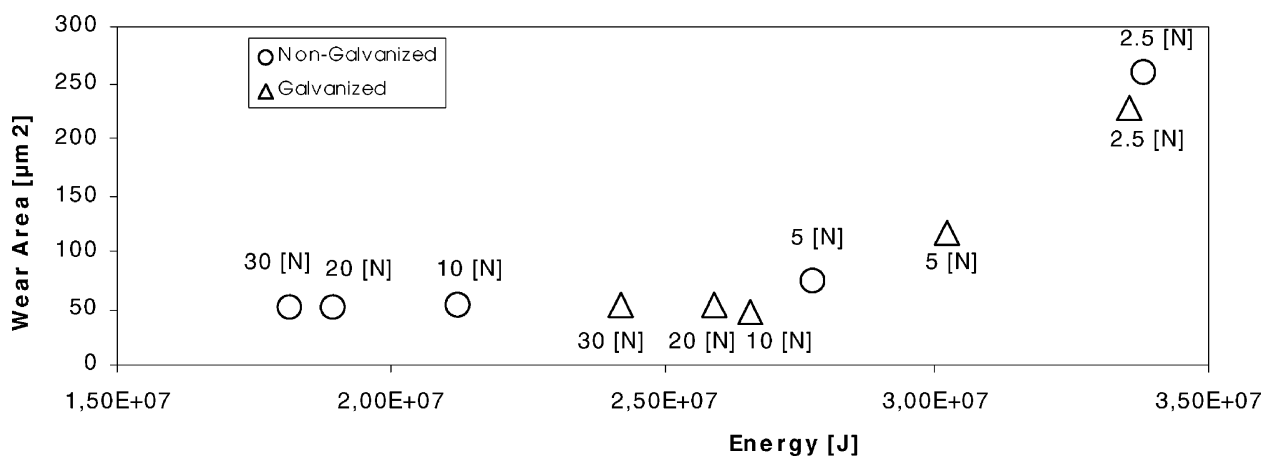

Fig. 9. Wear vs. energy for the various normal load condition fretting tests.

displacement. Fig. 10 summarises the influence of the relative displacement on the morphology of the wear scars for both galvanised and non-coated steel.

As regards the normal load, the displacement change has had an important effect on the fretting cycles. With increasing displacement amplitude, the fretting cycles varied from a linear and closed shape to a more open and almost trapezoidal shape (Fig. 11). The amounts of wear were evaluated and the results are shown in Fig. 12. For the smaller displacements, up to $16 \mu \mathrm{m}$, there is no damage. Above this value, there is a slight rise in wear with displacement increase up to $50 \mu \mathrm{m}$, and a marked increase in the transversal area of the wear scar for the biggest value of the displacement. Fig. 13 gives a plot of the transversal area of the wear scars as a function the total dissipated energy. Two zones can be identified; the first corresponds to values of the displacement amplitude up to $50 \mu \mathrm{m}$, which agrees very well with a linear relationship for the semi-logarithmic scale used. This zone shows a slight increase in wear with the dissipated energy. However, the test with the highest value of displacement results in a striking increase in wear.

Qualitatively, the results obtained agree very well with what was predicted by the Mindlin and Deresiewicz's model [4]. So, taking the results presented earlier into account, for stokes above $50 \mu \mathrm{m}$ the fretting regime changes from partial slip to gross slip, with a significant increase in the dissipated energy and amount of wear. Similar results were achieved by Campbell et al. for the fretting of pairs of ceramic steel specimens [11].
Concerning the role of the zinc film, no significant change was achieved in the fretting behaviour. When the dissipated energy reached high values, however, the amount of wear resulting for the coated surfaces was higher than for the uncoated ones. This was probably due to a combination of the lower hardness of the zinc coating and the effect of the iron oxide layers formed on the uncoated surfaces, leading to a decrease in the friction force (Fig. 11).

The shape of the obtained fretting loops is more rounded than it is usual for gross slip regime. Three main reasons can explain this particular shape, which are as follows:

- The effect of the compliance of the systems drops the slope of the elastic part of the fretting regime.

- The inertia of the moving parts smooth the suddenly transitions occurring on the begin and on the end of the slip, rounding the corners of the loops. This effect is emphasised for high frequency tests.

- Most of the tests have been done in elasto-plastic contact conditions. A recent study [16], shows that the plastic deformation of the contact smooth the transition between the stick and the slip parts of the fretting loops.

\subsection{Wear mechanisms}

As mentioned earlier, three fretting regimes were identified for the different test conditions. Different wear scar features and different shapes of the fretting cycles characterise each regime. For the stick regime, no damage appears on the test surfaces, while for the slip regime the damage

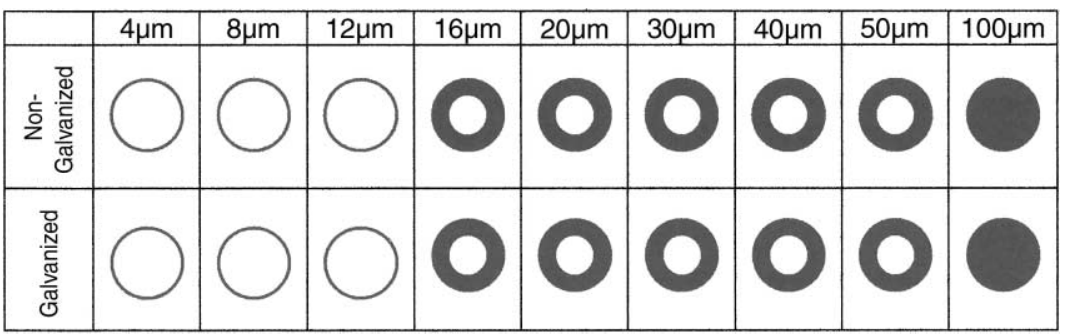

Fig. 10. Schematic representation of the damage features for the various displacement condition tests $(\mathbf{O})$ damage on the whole contact area; $(\mathbf{O})$ damage on the outer contact annulus; $(\bigcirc)$ no damage. 


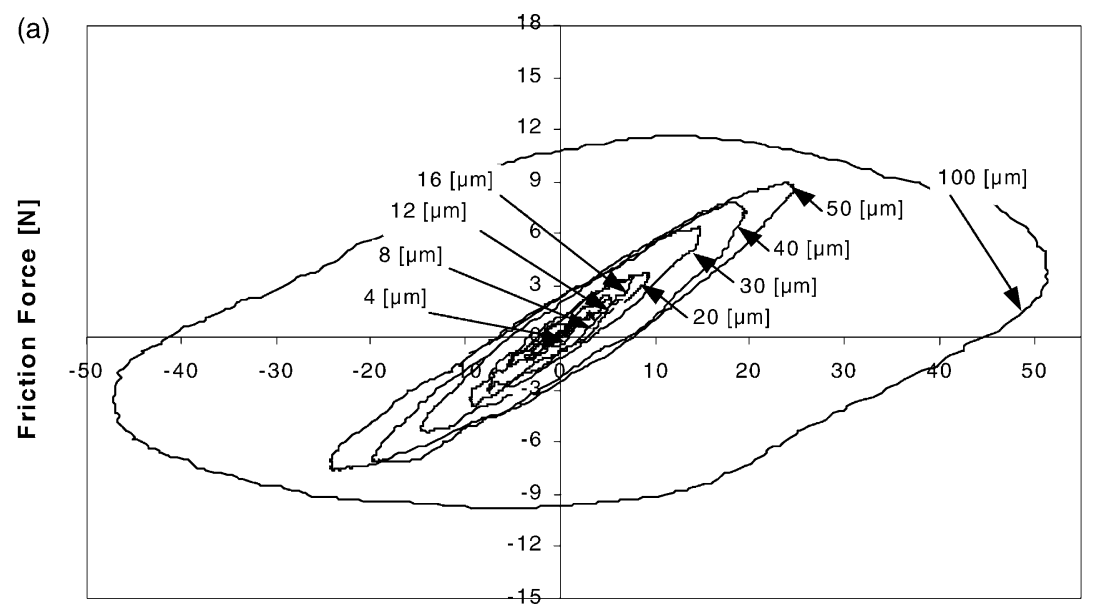

Displace me nt $[\mu \mathrm{m}]$

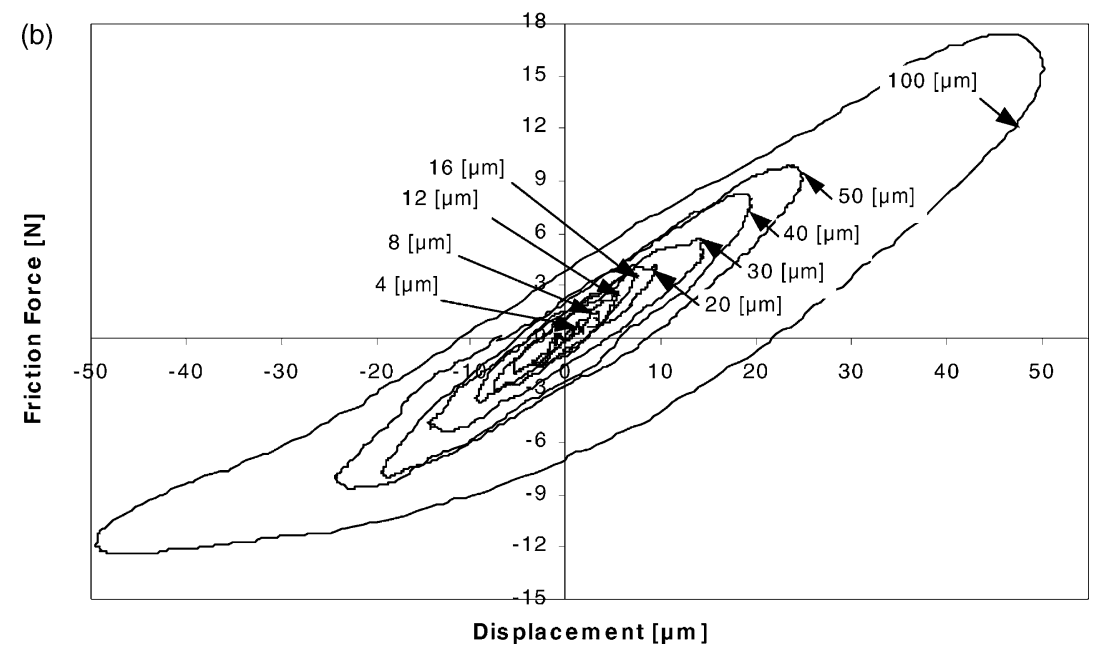

Fig. 11. Fretting loops for the various displacement condition tests (a) non-galvanised and (b) galvanised.

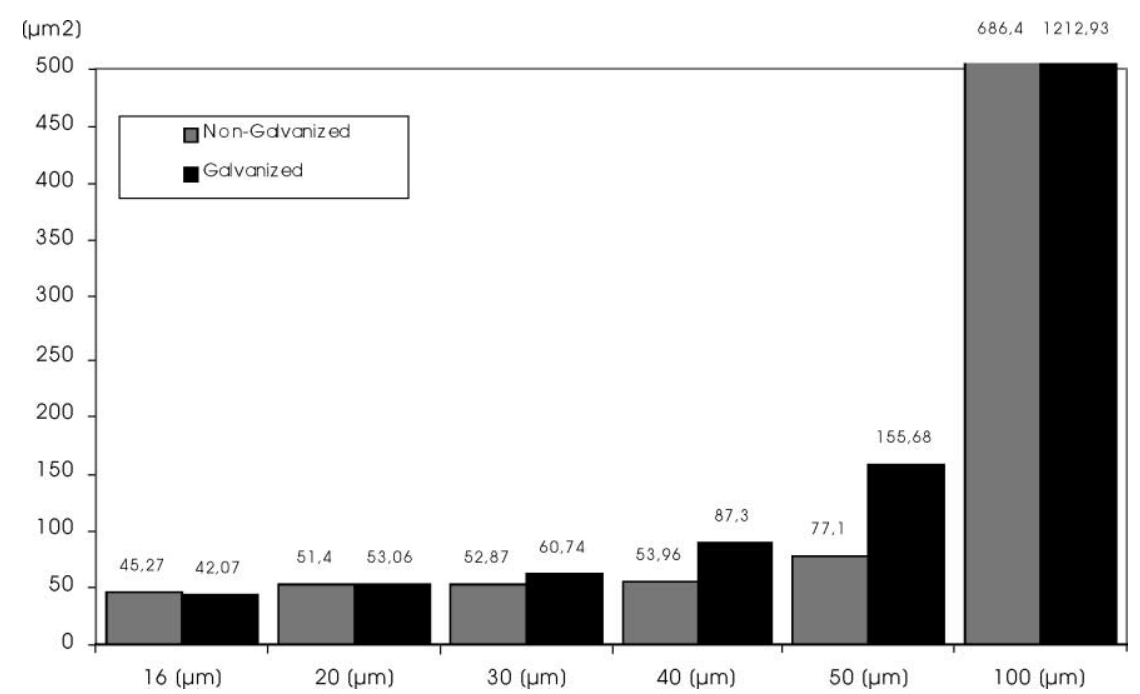

Fig. 12. Transversal area of the centre of the fretting scars for the various fretting stroke values. 


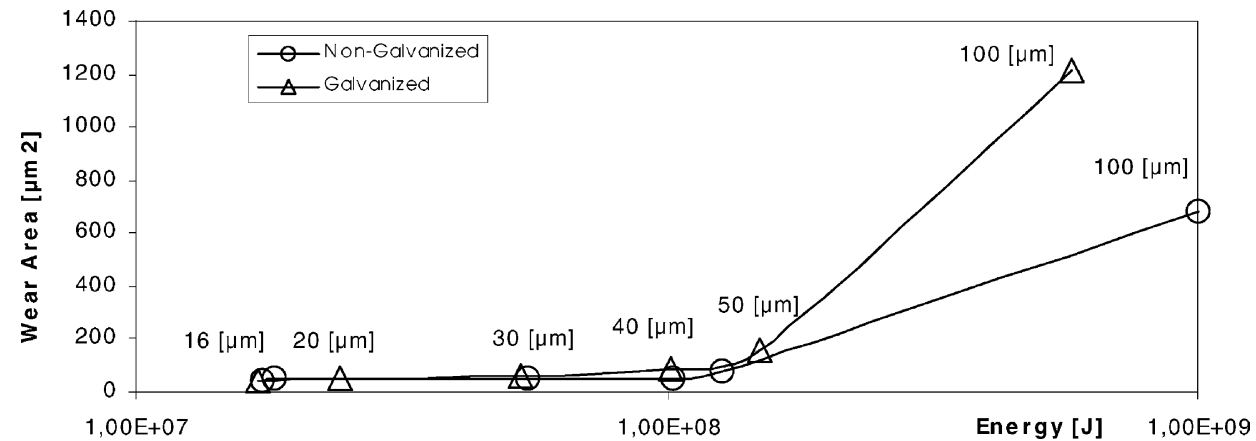

Fig. 13. Wear vs. energy for the various displacement condition fretting tests.
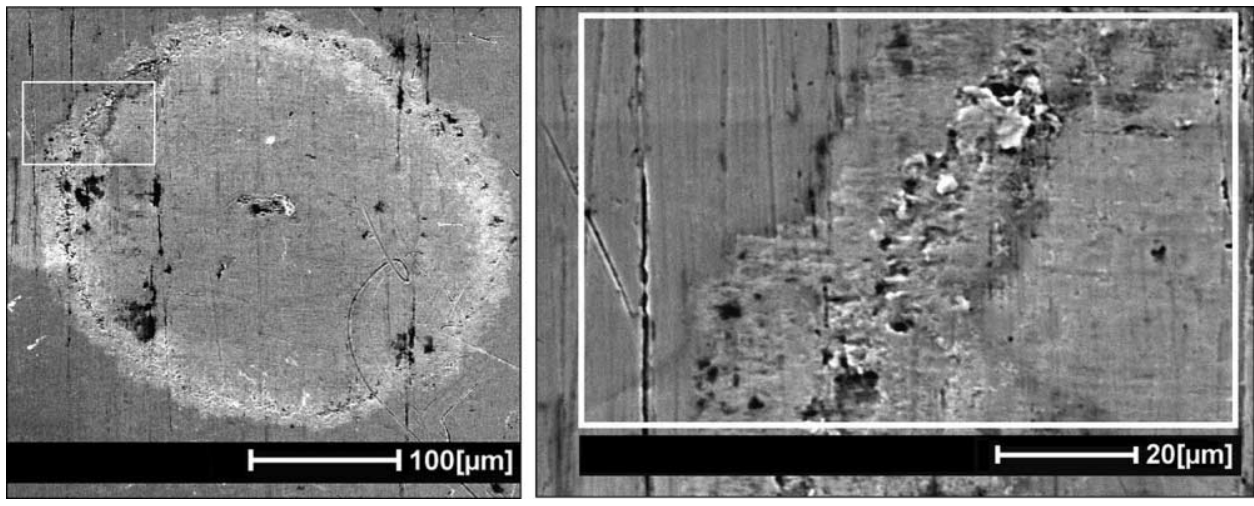

Fig. 14. SEM of a $20 \mathrm{~N}$ and $50 \mu \mathrm{m}$ fretting test scar of a galvanised specimen.
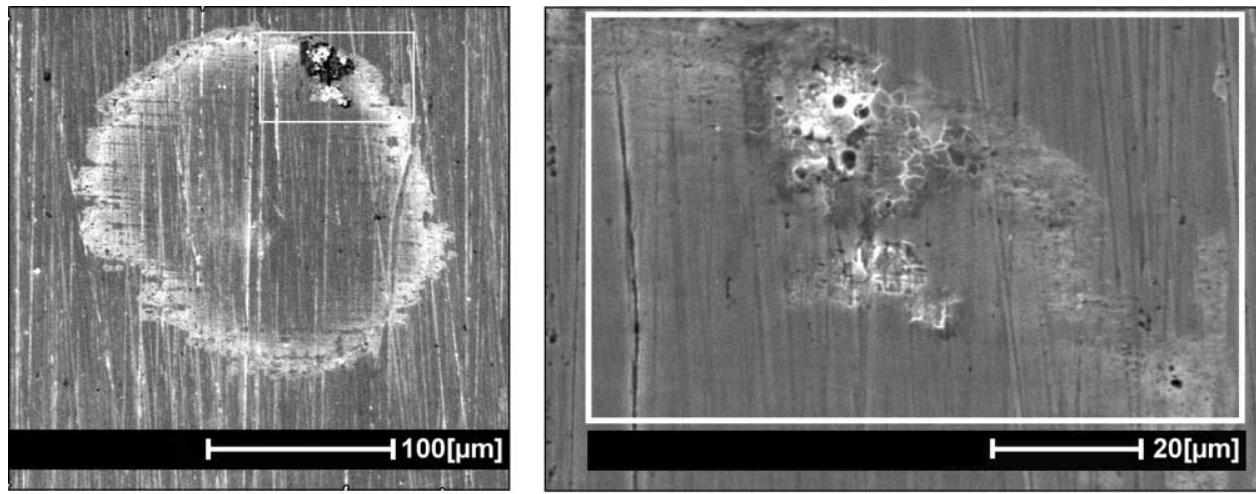

(a)
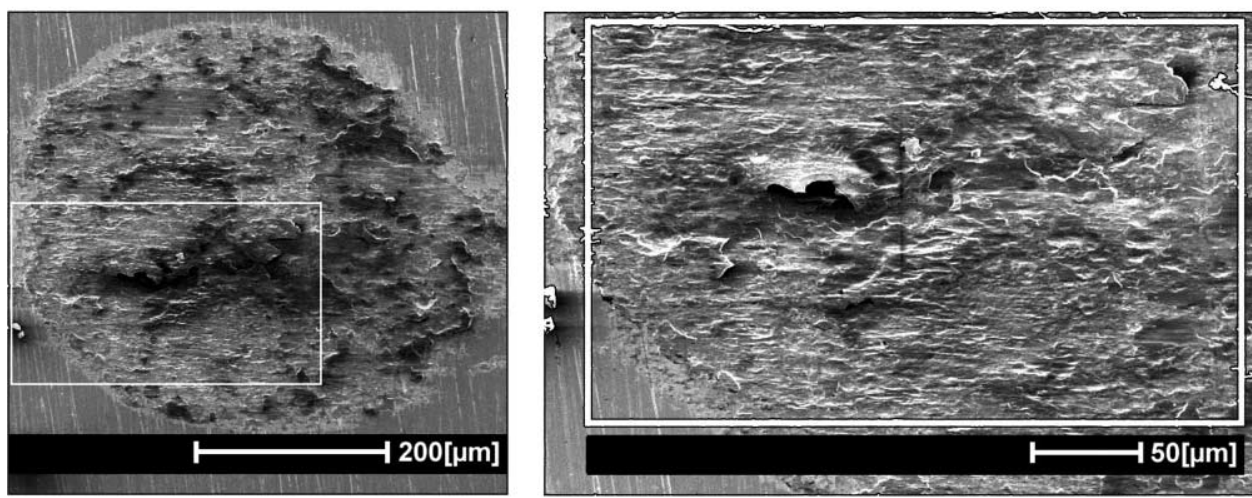

(b)

Fig. 15. SEM of non-galvanised specimens for (a) $20 \mathrm{~N}$ and $50 \mu \mathrm{m}$ fretting test and (b) $20 \mathrm{~N}$ and $100 \mu \mathrm{m}$ fretting test. 


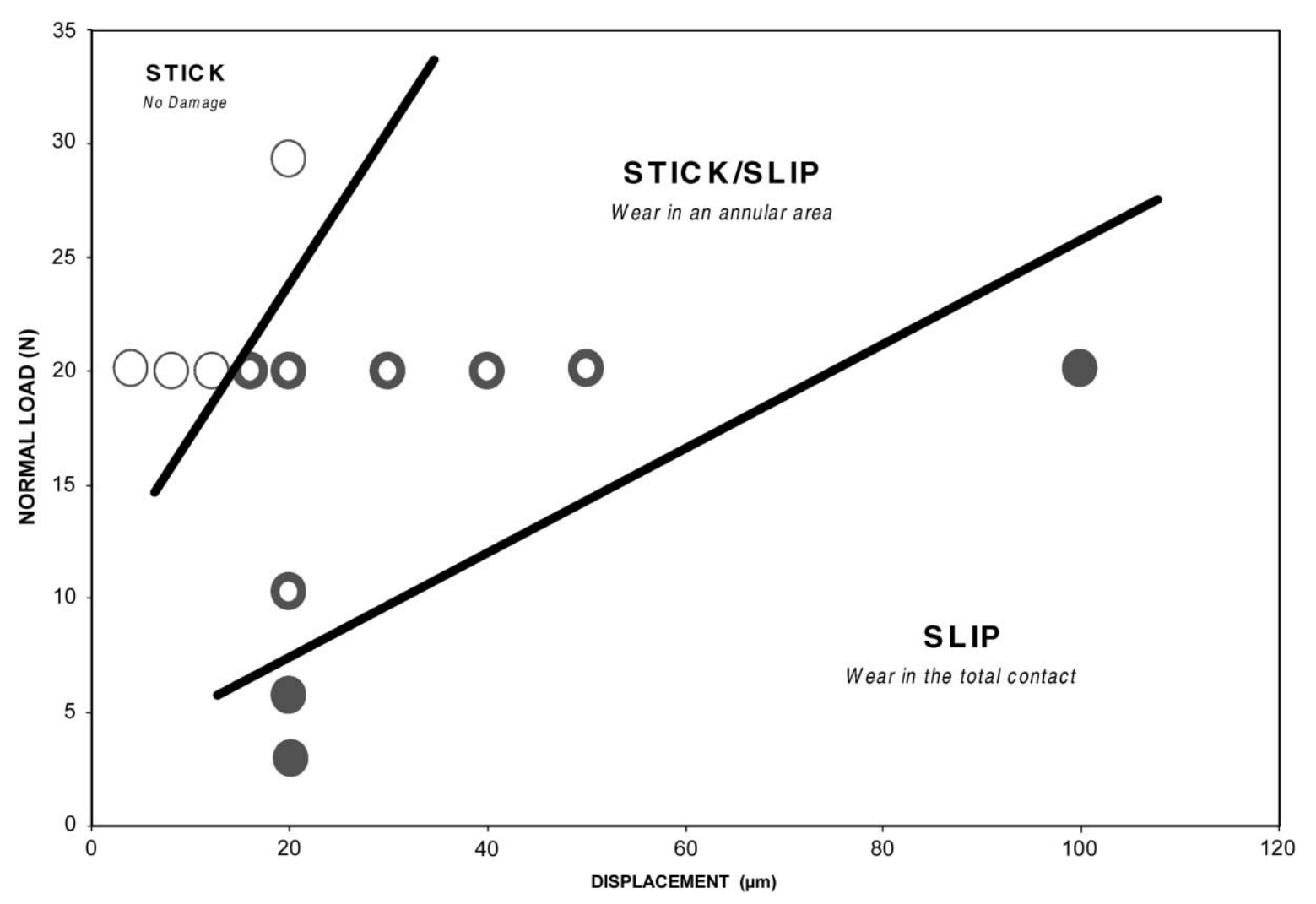

Fig. 16. Fretting map for the galvanised specimens.

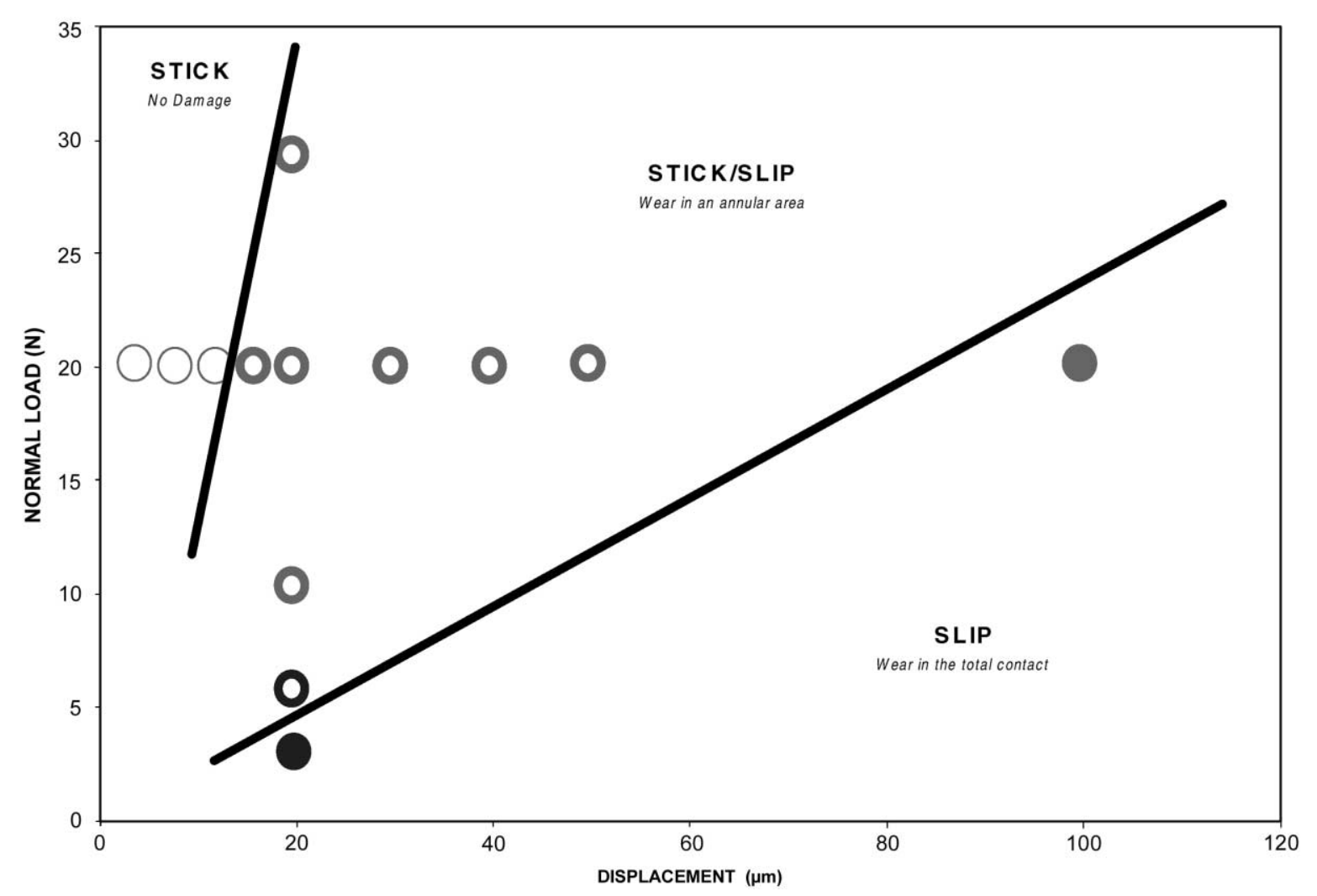

Fig. 17. Fretting map for the non-galvanised specimens. 
extended over the total contact area. For the mixed stick-slip regime, the damage occurred only at the borders of the contact, causing an annular damaged area.

Damage was caused in the galvanised specimens by the plastic flow of the film/coating, and only in some small spots did iron oxides appear, where all the coating had been removed (Fig. 14).

For the uncoated specimens, the damage was again caused by plastic flow, with some localised iron oxide spots. These features extend more or less throughout the contact surfaces, depending on the fretting regime (Fig. 15).

\subsection{Fretting maps}

All the results studied and presented above make it possible to construct a map of the normal load versus fretting stroke, defining the different fretting regimes for each type of material tested. These maps are given in Figs. 16 and 17, for galvanised and non-galvanised steels, respectively. As the number of test conditions was not extensive, it is not possible to confirm the exact separation of each regime with a high degree of accuracy, however it does seem that the mixed regime zone is smaller for the galvanised surfaces.

\section{Conclusions}

This study makes it possible to conclude that for the different normal load test conditions, the galvanisation did not significantly modify the fretting behaviour of the substrate, either quantitatively or qualitatively. The results show that for different normal load values, the fretting regimes did change. The slip regime occurred for both the galvanised and the non-galvanised specimens at the lower values of the normal load, while for the highest loads the stick regime occurred. For the intermediate values of load, the mixed stick-slip regime was dominant.

The fretting stroke condition tests also permitted identification of three different fretting regimes. For the smaller amplitude strokes, the stick regime was dominant and for the highest strokes the slip regime prevailed. For all the other stroke values, the mixed stick-slip regime was identified. As for the tests on the effect of normal load, galvanisation did not change the fretting behaviour of the substrate for the different values of the fretting stroke.
As above demonstrated, the distinction between the different fretting regimes is possible using different criteria, such as the morphology of the fretting scar, the wear amount, the shape of the fretting cycles and the friction energy.

\section{Acknowledgements}

The authors would like to thank the Portuguese Foundation for Science and Technology for their financial support to this research (Project Praxis XXI 2/2.1/ TPAR 2041/95).

\section{References}

[1] R.B. Waterhouse, Fretting wear, in: P.J. Blau (Ed.), ASM Handbook, Friction, Lubrication and Wear Technology, ASM, Materials Park, OH44073-USA, Vol. 18, 1992, pp. 242-256.

[2] R.C. Bill, Review of factors that influence fretting wear, ASTM-STP 780, 1982, pp. 165-182.

[3] L. Vincent, Y. Berthier, M.C. Dubourg, M. Godet, Mechanical Materials for Fretting, Wear 153 (1992) 135-148.

[4] R.D. Mindlin, H. Deresiewicz, Elastic spheres in contact under varying oblique forces, ASME Trans. J. Appl. Mech. E20 (1953) 327-344.

[5] G.M. Hamilton, L.E. Goodman, The stress field created by a circular sliding contact, J. Appl. Mech. 88 (1966) 371-376.

[6] R.W. Leonard, Precoated steel sheets, in: J.R. Davies (Ed.), ASM Handbook, Properties and Selection: Irons, Steels and HighPerformance Steels, ASM, Materials Park, OH44073-USA, Vol. 1, 1990, pp. 212-225.

[7] A. Ramalho, L.M. Correia, J.D. Costa, Fretting fatigue of zinc coated low carbon steel EN H320 M, Tribol. Int. 33 (11) (2000) 761-768.

[8] J. Halling, The tribology of surface films, Thin Solid Films 108 (1983) 103-115.

[9] http://www.matls.com.

[10] O. Vingsbo, S. Söderberg, On fretting maps, Wear 126 (1988) 131-147.

[11] P.Q. Campbell, J.-P. Celis, J.R. Roos, O. Van Der Biest, Fretting wear of selected ceramics and cermets, Wear 174 (1994) 47-56.

[12] S. Fouvry, Ph. Kapsa, H. Zahouani, L. Vincent, Wear analysis in fretting of hard coatings trough a dissipated energy concept, Wear 203-204 (1997) 393-403.

[13] S. Fouvry, Ph. Kapsa, L. Vincent, Analysis of sliding behaviour for fretting loadings: determination of transition criteria, Wear 185 (1995) 35-46.

[14] H. Mohrbacher, B. Blanpain, J.-P. Celis, J.R. Roos, The influence of humidity on the fretting behaviour of PVD TiN coatings, Wear 180 (1995) 43-52.

[15] P.-Q. Wu, H. Mohrbacher, J.-P. Celis, The fretting behaviour of PVD TiN coatings in aqueous solutions, Wear 201 (1996) 171-177.

[16] H. Serrano, Modelização de contactos cilindro/plano em solicitações de fretting, Modeling of cylinder/plan fretting contacts, Master Thesis, Universidade de Coimbra, Coimbra, Portugal, 2001. 